\title{
Needs and cost-effectiveness in health care priority setting
}

\author{
Erik Gustavsson ${ }^{1,2} \cdot$ Gustav Tinghög $^{2,3}$
}

Received: 21 February 2020 / Accepted: 26 March 2020 /Published online: 8 April 2020

(C) The Author(s) 2020

\begin{abstract}
How to balance the maximization of health and concerns for the worse off remains a challenge for health care decision makers when setting priorities. In regulatory guidelines these concerns are typically specified in terms of priority setting according to needs and priority setting according to cost-effectiveness. Still, it is often unclear when and why needs and cost-effectiveness diverge or overlap as guiding priority setting principles in practice. We conduct a comparative analysis of need and costeffectiveness in the context of health care priority setting. Based on theories of distributive justice we specify three normative interpretations of need and explicate how these relate to the normative basis for cost-effectiveness analysis. Using priority-setting dilemmas we then move on to explicate when and why need and cost-effectiveness diverge as priority-setting principles. We find that: (i) although principles of need and cost-effectiveness may recommend the same allocation of resources the underlying reason for an allocation is different; (ii) while they both may give weight to patients who are worse off they do so in different ways and to different degree; and (iii) whereas cost-effectiveness clearly implies the aggregation of benefits across individuals principles of needs give no guidance with regard to if, and if so, how needs should be aggregated. Priority setting according to needs or cost-effectiveness does not necessarily recommend different allocations of resources. Thus, the normative conflict between them, often highlighted in practice, seems exaggerated. For health policy this is important knowledge because unclear conceptions may obstruct an informed public discussion. Moreover, if decision-makers are to properly account for both principles they need to recognize the inconsistencies as well as similarities between the two.
\end{abstract}

Keywords Health needs $\cdot$ Health care needs $\cdot$ Principles of need $\cdot$ Priority setting $\cdot$ Rationing $\cdot$ Cost-effectiveness

\section{Introduction}

Priority setting in health care presents distinctive ethical challenges. One of the greatest tasks facing decision-makers in health care is how to balance concerns for equity with concerns for health maximization. In guidelines for health care priority setting these concerns are often specified in terms of cost-effectiveness and needs [1-4]. Despite the prominence accorded to these principles in priority setting, there seems

Erik Gustavsson

erik.gustavsson@liu.se

1 Centre for Applied Ethics, Department of Culture and Society, Linköping University, 58183 Linköping, Sweden

2 The National Centre for Priority Setting, Department of Health, Medicine and Caring Sciences, Linköping University, Linköping, Sweden

3 Division of Economics, Department for Management and Engineering, Linköping University, Linköping, Sweden to be considerable confusion about how these principles may serve as a basis for priority setting as well as how they relate to each other. For health policy this has severe consequences, not only because it hinders an informed public discussion but also, if decision-makers are to properly account for both principles they need to recognize the inconsistencies as well as similarities between the two.

The principle of cost-effectiveness (CEP) can widely be described as a rule that priority should be given to programs and interventions that maximizes health in society. To claim that priorities in health care should be based on costeffectiveness is often viewed as controversial (see e.g. [5-8]). The idea that priorities in health care should be based on some principle of patient need is less controversial and widely embraced in the bioethical literature as well as in official guidelines for priority setting [2-4, 9-16]. It seems also to be a notion to which health care professionals ascribe considerable importance [17]. However, what it would entail in practice to set priorities according to need often remains unclear. Moreover, many assert a conflict between setting priorities 
according to need and according to cost-effectiveness but when and why such a conflict arise is also unclear.

The objective of this paper is to characterize how concepts of need may be specified for health care priority setting and explore how these specifications relate to CEP. Drawing on two concepts of need (Health Need and Health Care Need) we explicate how need-based distribution can be understood in terms of theories about distributive justice. We then explicate what normative work principles of need can do that CEP cannot, and vice versa. We conclude that the often-asserted conflict between need principles and cost-effectiveness in priority setting is overstated once need is appropriately - and conventionally - conceptualized. However, since they approach priority setting form different perspectives (patient vs. population level) both are necessary ingredients in sensible priority setting.

\section{Methods}

The analysis in this paper unfolds in the following way. First, a conceptual framework for clarifying needs and cost effectiveness, respectively, is developed and specified. Second, this framework constitutes the ground for a comparative ethical analysis. The underlying normative assumptions of costeffectiveness are outlined and clarified. We then outline three ways in which priority setting according to need may be understood in terms of distributive justice, namely needs as egalitarianism, needs as prioritarianism, and needs as sufficiency. Third, these three specifications of need are employed in order to delineate the differences and similarities between priority setting according to need and priority setting according to CEP. The analysis also employs a number of cases of priority setting in order to explore the implications of these different normative positions.

\section{Health care priority setting according to need}

The need for health can be understood as the gap between current health and desired health (Fig. 1). A person's desired health does not necessarily coincide with optimal health, since individuals typically desire less than optimal health; especially as we get older and view some deterioration in functionality as a natural course of aging. Further, the gap does not necessarily only involve one's current health; it could also involve the risk for future ill health. For example, when we take vaccine as a preventive measure we are trying to reduce the gap between the current risk and the desired risk of becoming sick.

The defined concept of health need $(\mathrm{HN})$ as a gap between current health and desired health does not, however, yield sufficient information for us to make priority setting decisions
Optimal Health

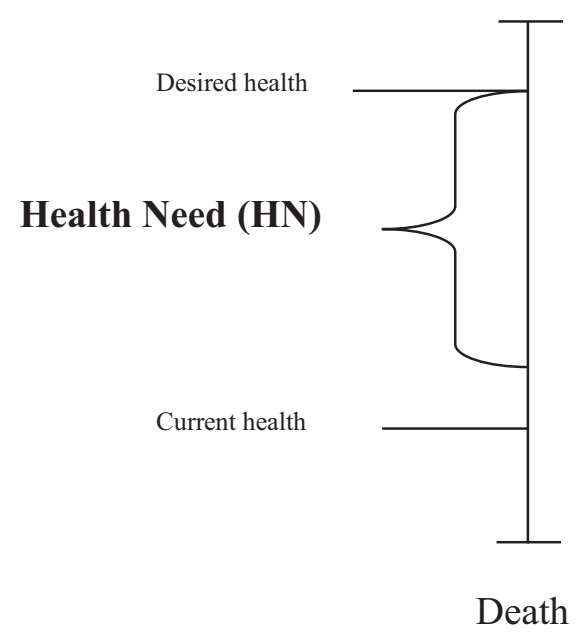

Fig. 1 Graphical illustration of Health Need (HN)

on the basis of need. We must also assess what the individual has a need for. What kind of health care is needed to potentially reduce the gap between current health and desired health? For a patient suffering from end stage renal disease the health gap might for example be reduced by kidney transplantation.

As illustrated in Fig. 2, two prerequisites must be present for a health care need ( $\mathrm{HCN}$ ) to arise: (i) A Health Need must exist, i.e. a gap between current health and desired health. (ii) An intervention that potentially can reduce the health gap must exist. Hence, one cannot need an intervention from which one cannot benefit [18-21].

The distinction between $\mathrm{HN}$ and $\mathrm{HCN}$ is important because the major determinant of individuals' health is not health care, but other social determinants [22]. It is also important to note that while it is quite uncontroversial to say that the cost associated with an intervention is a relevant factor for setting

\section{Optimal Health}

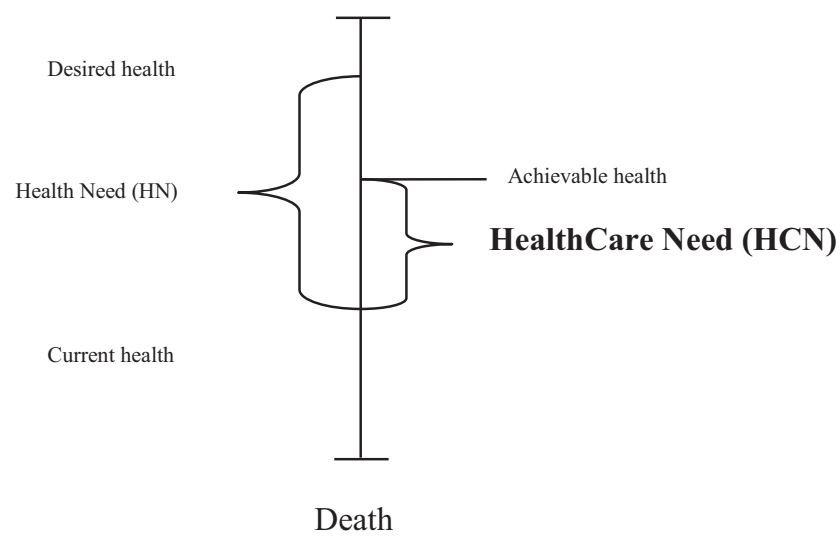

Fig. 2 Graphical illustration of Health Care Need (HCN) 
priorities in general, this does not imply that $\mathrm{HN}$ or $\mathrm{HCN}$ is dependent on the size of the associated cost (see further e.g. [13-15]).

\subsection{Three accounts of need as a distributive principle in health care priority setting}

In this section we will relate $\mathrm{HN}$ and $\mathrm{HCN}$ to three normative accounts of distributive justice. We shall refer to these accounts as: needs as egalitarianism, needs as prioritarianism and needs as sufficientarianism. These accounts of distributive justice all account for patients' $\mathrm{HN}$ as well as their HCN. Although providing different moral grounds for why and to what extent weight should be given $\mathrm{HN}$ and $\mathrm{HCN}$, respectively.

\subsubsection{Needs as egalitarianism}

Egalitarian theories are based on the idea that equality ought to be promoted in some sense, or that inequality should be avoided [23-26]. Equality is a complex idea to operationalize, and there are several ways in which an outcome can be made better or worse in terms of (in)equality [25]. A common suggestion is equality of outcome, i.e. we should allocate resources in such a way that the level of health is as equal as possible among patients. Another suggestion is equality of opportunity, i.e. we should allocate resources in a way that gives people an equal chance to achieve their greatest potential for health. While equal opportunities are important aspects in health policy, and there is a large literature related to the importance of social determinants to health [22, 27-30] and the role of responsibility for ill health [31-35], we will not focus on this conceptualization of need here. Instead we will focus on outcome egalitarianism as one way to distribute resources among needs. For example, this is how the principle of need is interpreted by the Swedish commission [3] when they state that it, in part, prescribes "....an effort to equalize the outcome of care as far as possible" (p. 105)".

To specify needs in terms of equality makes it a comparative account of justice, implying that what matters morally is that someone is worse off than someone else. For example, Rawls's difference principle [24] gives a special consideration to the worst off in that it prescribes that "...inequalities are to be arranged so that they are...to the greatest benefit of the least advantaged..." (p. 53). In practice, the difference principle often implies giving priority to the worst off.

The difference principle as such does not, however, ascribe any particular importance to the extent to which a patient can benefit from an intervention. This absolute priority to the worst off implies that the non-worst off do not matter from a justice point of view [23]. Such a strict interpretation of egalitarianism is sometimes referred to as the Sickest first principle, which says that absolute priority should be given to the worst-off individuals [16]. In terms of needs, following this distributive judgment would be to distribute resources on the basis of the magnitude of a person's HN. The main objection to such distributions is the "bottomless pit objection", the idea that it seems unreasonable to allocate all resources to a small number of (very needy) patients [36], especially since patients who are almost as needy may be benefitted a lot more for the same resources.

\subsubsection{Needs as prioritarianism}

To interpret needs as a prioritarian principle implies that the moral importance of a benefit diminishes as the absolute level of health increases [16]. Thus, it matters more to benefit a person the worse off that person is. As opposed to needs as egalitarianism which is concerned with a comparative level of justice, need as prioritarianism is concerned with people's absolute levels [37-39]. That is, what matters morally is not that some are worse off in relation to others but rather that some are badly off period, or that some are worse off than they could have been.

Prioritarianism may be well understood in terms of two theses: (i) maximizing well-being and (ii) priority to the worse off. A prioritarian need principle may accordingly be constructed in very different ways. At one extreme, most weight would be put on the latter thesis, which means a focus on the $\mathrm{HN}$ rather than the HCN. This interpretation is also close to the sickest first principle. At the other extreme most weight would be put on the former thesis which entails a focus on the $\mathrm{HCN}$ and prioritarianism would then barely be distinguishable from a utilitarian principle.

\subsubsection{Needs as sufficientarianism}

When interpreting needs in terms of sufficientarianism what matters morally is that people are located above a certain minimal degree of health (or threshold). Thus, needs as sufficientarianism is, like prioritarianism, concerned with people's absolute levels of health. Likewise, needs as sufficientarianism can also be characterized by two theses, the positive and the negative thesis $[40,41]$. The former implies that we should seek to lift the people who are located below the threshold above it. The latter implies that there is no reason to lift the people who are already located above the threshold any further.

The only way to interpret need as sufficientarianism solely on the basis of these two core elements is to say that we should prioritize people below the threshold to elevate them above the threshold [16, 42]. However, many would argue that this is an implausible distributive principle since there may be strong reasons for lifting people from, say, very far away from the threshold to a level very close to it (but yet not above it). Accordingly, need as sufficientarianism gives no guidance 
concerning how to prioritize among people below the threshold. Thus, sufficiency principles are incomplete in that they have to be combined with some other distributive principle when it comes to prioritizing among the people below the threshold $[10,16,37]$.

\subsection{What is the currency of distribution according to need?}

Priority setting according to need does not in itself provide any answer as to what should be distributed. Commonly proposed as filling this gap is some notion of health or some broader notion of well-being. A well-known definition of health is the one stated by the World Health Organizations: "Health is a state of complete physical, mental and social well-being". According to such a definition of health, combined with a principle of need, almost anything would qualify as a need for health care. Still, there are more nuanced theories of health. In this context it is enough to distinguish between three kinds of theories of well-being and two kinds of theories of health.

\subsubsection{The concept of well-being}

Theories of well-being are often understood as either hedonistic theories, desire-fulfilment theories or "objective list" theories. (i) Hedonism - a person's life goes well if it contains a balance of pleasure (or happiness) over pain (or unhappiness). (ii) Desire-fulfilment theories - a person's life goes well if it contains a balance of desire-fulfilment over having one's desires frustrated or having one's aversions fulfilled. (iii) Objective list theories - a person's life goes well if it contains a number of objective values such as autonomy and friendship. These values are objective in the sense that they are considered to be so independently of a person's attitude towards them.

\subsubsection{The concept of health}

Theories of health are often characterized as either biomedical (of which the bio-statistical theory is an influential example) or holistic. (i) The bio-statistical theory of health [43] - a person is healthy to the extent that his or her organs and tissues are functioning normally (i.e. contribute to his or her surviving or reproduction) given a statistically normal environment. (ii) The holistic theory of health [44] — a person is healthy to the extent that he or she has the ability to achieve the vital goals necessary and sufficient for his or her minimal happiness.

Whereas there is a tendency towards objective theories of well-being among need theorists [42, 45-47], it remains an open question whether this is the best approach in a contemporary health care context. Accordingly, principles of need may be constructed with several ideas about human good as its currency of distribution, which, in turn, may prescribe different ways of allocating resources, more or less close to what CEP implies.

\section{Priority setting according to cost-effectiveness}

Cost-effectiveness is a measure of the cost of a service in relation to some unit of its effectiveness. The outcome of cost-effectiveness is usually expressed in terms of an incremental cost-effectiveness ratio (ICER), where the effect is the denominator and the corresponding cost is the numerator (as shown in the ICER formula below). In health care the costeffectiveness ratio could be viewed as a "price-tag" on the additional gain in health achieved by switching from current practice to the new strategy (for example $€ 5000$ per gained life year or quality adjusted life year). If the willingness to pay is greater than the price, the new health program can be said to be cost-effective. Thus, when a health program is said to be cost-effective it simply indicates that the perceived benefits outweigh the costs.

Incremental Cost Effeciveness Ratio $=\Delta \operatorname{Cost} / \Delta$ Effects

\subsection{Cost-effectiveness as a distributive principle in health care}

In a normative sense cost-effectiveness can be described as a maximization principle, i.e. resources should be allocated in such a way that the total sum of health is maximized. As regards health, this translates into a distribution of health care resources that maximizes the total sum of health in society. This means that priority setting in accordance with CEP only ascribes importance to the extent to which patients can benefit from interventions, while giving no extra weight to the worse off. That is, in terms of needs CEP focuses only on the HCN and pays no attention to the $\mathrm{HN}$.

Although cost-effectiveness theoretically could include any form of outcome measure in the denominator, the welfare economic foundation of cost-effectiveness prescribes that it should be a representation of individuals' utility. Formula 2 is the ICER formula with utility as the currency for distribution, i.e. the incremental cost-utility ratio.

Incremental Cost Utility Ratio $=\Delta$ Cost $/ \Delta$ Utility

As a consequence of the emphasis on utility, costeffectiveness is closely related to utilitarianism, which is one kind of maximizing approach and which focuses on some representation of utility $[48,49]$. To understand the basis for 
the utilitarian normative claim it may be helpful to disentangle the following three elementary requirements: (i) welfarism requires that the goodness of a state of affairs be a function only of the utility information regarding that state; (ii) maximization requires that utility information regarding any state be assessed by the sum of utility in that state. This means that utilities should be aggregated across individuals; and (iii) consequentialism requires that the rightness of an action be assessed on the basis of the outcome or consequence it produces.

A central concept when it comes to understanding the meaning of cost-effectiveness as a normative principle is cardinality. For health benefits to be summed together in a way that is in accordance with utilitarianism they need to be represented by a valid cardinal utility function. Cardinal utility captures the strength or intensity of preference differences as opposed to ordinal utility, which only captures the ranking of preferences. For example, suppose that a state of perfect health in $1 \mathrm{yr}$ is assigned a health value of 1 , a state of angina is assigned a health value of 0.6 , and a state of severe depression is assigned a value of 0.2 . If the health value is represented by a valid cardinal utility function we can say not only that perfect health is preferred to a state of angina, but also that it is preferred with exactly the same intensity as a state of angina is preferred to a state of severe depression. Hence, it is also possible to aggregate these utilities across individuals and say something about the desirability of different aggregated outcomes.

Quality Adjusted Life Years (QALYs) is the measurement most frequently used to evaluate health benefits in cost-effectiveness, since it is the utility-based measurement of health-related quality of life which has been developed in accordance with welfare economic theory [50]. For QALYs to represent a cardinal utility function they need to reflect the intensity of individuals' preferences. This implies that individuals should prefer the option that maximizes the expected amount of QALYs as being a representation of individual utility in respect of healthrelated quality of life. If not, QALYs cannot be taken to reflect individual utility in respect to health [51].

A related basic tenet of economic and psychological models is the assumption that individuals generally exhibit decreasing marginal utility $[52,53]$, and that this also is related to improvements in health. The rationale for this is that a particular health improvement is likely to create greater utility improvement for a severely ill individual than for a healthier individual. For instance, a paraplegic who suddenly recovered the ability to move a finger would most certainly derive a higher increase in utility than would an otherwise healthy individual who recovered the same ability. Owing to the existence of diminishing marginal utility it may be argued that cost-effectiveness has an inbuilt mechanism towards benefitting the worse off. This is because they will derive a higher increase in utility from a given health improvement than will individuals who are already relatively well off. That is, if Ali is severely impaired and Boris is slightly impaired and they receive an equal increase in health (in absolute terms) Ali will ascribe a higher value to the increase than Boris.

\subsection{What is the currency of distribution according to CEP?}

QALYs are the most widely used measure of health benefits in CEP. QALYs are often assumed to represent utility, which in turn is dependent on health status (Q) and the number of life years. This can be expressed by means of the following formula:

$$
\mathrm{QALYs}=\mathrm{U}(\mathrm{Q}, \mathrm{T})=\mathrm{V}(\mathrm{Q}) * \mathrm{~T}
$$

where $U(Q)$ is the value function of quality measured on a scale between 1 (full health) and 0 (death) corresponding to the value attached to the health state, which is multiplied by life years (T). For instance, an individual with a level of 0.5 who will live 10 additional life years will generate $5(0.5 * 10)$ additional QALYs. Hence, the QALY should not be equated with health or well-being but should be understood as a measure of the utility an individual attach to a state of health which may be achieved with intervention as compared with some other state of health which would follow without intervention.

Individual preferences used to evaluate health states are frequently found to violate conditions for QALYs' representation of utility [54]. This has led to the emergence of a nonwelfarist approach (which is, confusingly, often referred to in the literature as extra-welfarism), where QALYs are interpreted as being an indication of health, but the actual utility does not necessarily have to change proportionally to the size of QALY gains. If this view is correct CEP no longer fits into the utilitarian framework since QALYs do not then represent a valid cardinal utility function.

\section{When and why needs and cost-effectiveness overlap as guiding principles}

To understand the relation between need principles and CEP when their implications may overlap as priority setting criteria and when they do not, we will consider a hypothetical resource allocation case. We shall consider this case both at the bedside and the policy level since studies have shown that people make different rationing decisions depending on the scope of the decision $[55,56]$. For simplicity reasons we assume that there are only three health states that people can experience: 
(a) No impairment - a condition in which one has full health, preference value: 1

(b) Slight impairment - a condition that renders it difficult for one to move around, preference value: 0.6

(c) Severe impairment - a condition that leaves one bedridden a large part of the day, preference value: 0.2

Each health state is associated with a preference value between 0 (death) and 1 (full health). This preference scale between 0 and 1 is cardinal implying that the difference between 0.1 and 0.2 is as large, in terms of preference intensity, as the difference between 0.9 and 1 .

\subsection{Priority setting at the bedside level}

Starting by examining rationing at the bedside level let us assume that there are three patients: Ali, Boris, and Cecilia are all in need of health care, and the cost of treating them is the same.

Ali is at severe impairment $(0.2)$ and can be benefited to no impairment (1) i.e. total increment is 0.8 .

Boris is at slight impairment (0.6) and can be benefited to no impairment (1) i.e. total increment is 0.4 .

Cecilia is at severe impairment $(0.2)$ and can be benefited to slight impairment (0.6) i.e. total increment is 0.4 .

In a choice between whether to treat Ali or Boris, a focus on their $\mathrm{HN}$ as well as a focus on their $\mathrm{HCN}$ would prescribe that Ali should be prioritized. However, understanding needs in terms of different distributive theories of justice give preference to Ali for different reasons: (i) When employing an egalitarian distribution among needs the reason for choosing Ali is the comparative factor, i.e. that Ali has a greater $\mathrm{HN}$ in relation to Boris; (ii) when employing a prioritarian distribution among needs the reason for choosing Ali is that it matters more to benefit him as he has a greater $\mathrm{HN}$ (in absolute rather than relative terms); (iii) when employing a sufficientarian distribution among needs the reason for choosing Ali is that Ali's $\mathrm{HN}$ is great to the extent that he is located below the threshold (given that the threshold level is placed at, for example, preference level of 0.4). Note, however, that if there was a fourth person David, located at 0.5 and who could be benefitted to 1 , sufficiency principles would be indifferent between Boris and David even though David is worse off than Boris.

This course of action also follows from CEP and does so because it provides the greatest net sum of utility; in this way CEP gives indirect priority to the worse off. Note that while any need principle does so because Ali is worse off this is a mere consequence of CEP. Consequently, while there is no necessary conflict between principles of need and CEP in terms of which allocation decision, there is an important difference between CEP and principles of need regarding the underlying reason for why Ali should get priority over Boris.

In a choice between whether to treat Boris or Cecilia any weight given to the $\mathrm{HN}$ imply that Cecilia ought to be treated instead of Boris since Cecilia's HN is greater. Again, an egalitarian distribution among needs would have this implication based on the comparative factor, a prioritarian distribution because Cecilia has a greater $\mathrm{HN}$ in absolute terms while a sufficientarian distribution among needs opts for Cecilia because her $\mathrm{HN}$ is great to the extent that she is located below the threshold while Boris is not. Priority setting according to CEP, however, would be indifferent since Cecilia and Boris' HCNs are equally great (both alternatives generate the same increase in utility).

It may be argued that CEP indirectly gives increasing weight to people the greater their $\mathrm{HN}$ are and hence has already accounted for the importance of being worse off. If we assume that people's preference value is capturing utility, CEP accounts for being worse off as the thesis of diminishing marginal utility adjusts for this. Thus, it would necessitate a larger health increase in absolute terms to move from 0.2 to 0.6 than from 0.6 to 1 . This implies that the extent to which CEP accounts for the importance one may ascribe to the extent to which one has a great $\mathrm{HN}$ being worse off partly depends on the extent to which the thesis of diminishing marginal utility for health is true, and to some extent on the adequacy of the methodology one employs to assess utility (see e.g. [54] for further discussion on the validity of utility measurements). In contrast, any principle of need involves a normative claim that there is something of special moral importance about having large $\mathrm{HN}$ (being worse off), regardless of whether, and if so to what extent, the preference value for different health states accounts for the diminishing value of health.

Along these lines it may be argued that decision-makers, who take both some principle of need and CEP into account, are unknowingly including the same moral value twice when setting priorities, i.e. they are double counting the moral value of being worse off. But even though CEP may account for the size of some people's HNs, the normative implication of principles of need, again, in any version is that there should be additional weight put on health improvements accruing to people the greater their $\mathrm{HN}$ is. Hence, the moral value of being worse off is not double counted. Rather principles of need ascribe extra weight in addition to whatever concern for the worse off accounted for by diminishing marginal utility.

In practice this line of reasoning could appear when decision-makers apply some threshold level for what society considers to be a reasonable cost per QALY, and fund interventions with a cost per QALY below the threshold but not above. Traditionally when setting priorities according to CEP a key normative assumption is that a QALY is of equal value irrespective of to whom it accrues [57]. That is, it is equally 
valuable independent of the size of the HN carried by the patient (or patient group). This implies that society applies some threshold level for a reasonable cost per QALY. Interventions below the threshold get funding while interventions above do not. Setting priorities according to principles of need, however, does not involve such a normative assumption. Instead, an intervention for a patient with a higher cost per QALY could be justified if it relates to a patient who has a greater HN. For example, this is illustrated by the approach outlined in the final report laid out by the Norwegian Committee on Priority Setting in the Health Sector in 2014 $[58,59]$.

Finally, in a choice between whether to treat Ali or Cecilia, the recommendation given by CEP is to prioritize Ali rather than Cecilia since this maximizes utility gained. One may interpret principles of need as being indifferent with regard to who should get an intervention since both patients' HNs are equally great. For example, that is what the sickest first principle would imply as this principle exclusively focuses on the greatness of the HN. However, it could be argued that the more a patient is benefited (i.e. the greater his or her $\mathrm{HCN}$ is) the stronger his or her need-based claim is [16]. Hence, also in this case principles of needs and CEP may imply the same course of action, and in this case for more similar reasons.

\subsection{Priority setting at the policy level}

To explore aspects relating to how the different approaches relate to the issue of aggregation of health benefits across individuals, let us consider the same case at the policy level. This entails making decisions about treatments for specific patient groups.

Patient group A contains a small number of patients which are (in all relevant aspects) like Cecilia (at 0.2 and may be benefited to 0.6 ).

Patient group $B$ contains a somewhat larger number of patients which are (in all relevant aspects) like Boris patients (at 0.6 and may be benefited to 1 ).

As in the bedside case, we assume that the total cost of treating the two groups is the same. Hence, there is a lower cost per health unit to get patients from group B from 0.6 to 1 than to get patients from group A from 0.2 to 0.6 . The application of CEP as the guiding principle here would imply that group B rather than A should get priority, since this allocation provides the greatest sum of aggregated utility.

How does principles of need relate to such a case on the macro level and aggregation? Whereas the conventional need principles could easily be applied to the bedside case their implications at the policy level is less clear. In regulatory guidelines it is sometimes suggested that principles of need are incompatible with aggregation [3]. But this seems like a rather implausible view in practice given that; if decision makers are to take costs into account at the policy level (which seems quite uncontroversial) this implies an opportunity cost, i.e. to consider how a given resource could have been used elsewhere. It seems difficult to account for the opportunity cost if all kinds of aggregation are prohibited. A more plausible principle of need should therefore arguably allow for some restricted form of aggregation. To characterize a method of aggregation compatible with ideas about need-based priority setting is an important task with regard to the plausibility of principles of need [60].

\section{Concluding discussion}

The objective of this paper was to characterize ways in which concepts of need may be specified for health care priority setting and explore how these various specifications relate to CEP. Following this objective, we have identified three key aspects that policymakers should recognize in order to properly distinguishing between priority setting according to needs and priority setting according to cost-effectiveness.

First, a need-based approach and cost-effectiveness do not necessarily imply different recommendations when setting priorities. This is only true to the extent one interprets "priority setting according to need" as "priority setting according to HN, i.e. health need" as we have explicated. However, it should be noted that even though they often prescribe the same allocation of resources they do so based on different underlying moral reasons. While medical ethics has a long tradition of focusing on protecting the rights and concerns of the individual, welfare economics and health economic evaluation, in contrast, have an impersonal focus which gives little or no concern for individual needs unless it affects the health of society as a whole. Although this difference, in point of departure, might seem obvious, it is seldom explicated when discussing health care priority setting. This difference is echoed when trying to understand why priority setting following from a need-based approach and priority setting following from a cost-effectiveness approach typically are seen to be in sharp conflict.

Secondly, whereas priority setting according to costeffectiveness clearly allows for aggregation of benefits across individuals it is less clear how aggregation should be dealt with when setting priorities according to needs. Following from the community-oriented view of ethics embedded in a cost-effectiveness focused approach, aggregation of benefits across individuals is implied. Thus, small benefits to the many may outweigh large benefits for the few. This is one feature of priority setting in accordance with CEP that may not be in line with what citizens think is the right way to set priorities, as 
exemplified by efforts made to set priorities based on costeffectiveness [61]. The general opinion seems rather to be that it is better to give priority to large benefits for a few individuals over equally large or larger aggregate benefits consisting of very small benefits for each of a great many more individuals. A need-based approach, however, is open to different rationales for how to deal with the aggregation of benefits. This may lead to a situation in which decisionmakers more commonly rely on CEP rather than needs on a macro level. In order to be applicable as an action-guiding principle on a policy level, need-based approaches should be further developed so that it allows for some restricted form of aggregation.

While it is difficult to agree on the proper principles for health care priority setting, there seems to be quite large agreement that we should give some priority to the worse off. That is, weight should be ascribed to the size of people's HNs. Our third conclusion relates to the belief that a need-based approach only focuses on the worst off while CEP does not give any consideration to the worse off. This belief is also incorrect for at least two reasons. First, the claim that priority setting according to need implies absolute priority to the worst off presupposes that need-based distribution equals distribution according to $\mathrm{HN}$ rather than $\mathrm{HCN}$. Second, there are at least two ways in which CEP may ascribe weight to the worse off: (a) to the extent it is true that QALY represent utility the thesis of diminishing margin utility account for weight to the worse off, (b) to the extent the preferences of the general public and their willingness to pay for a QALY are incorporated as equity weights CEP does give priority to the worse off. Hence, our discussion suggests that while priority setting according to need cannot plausibly be understood as giving priority according to $\mathrm{HN}$ it is not the case (given the assumptions presented above) that CEP has no concern for the worse off whatsoever. Rather, principles of need give weight to the worse off directly while CEP does so indirectly. The former involves a substantial normative claim that being worse off has some special moral importance while the latter assumes that the thesis of diminishing marginal utility accounts for any such importance or incorporates equity weights. Thus, to set priorities on the basis of need suggests that we should be prepared to pay more for individuals with greater HNs rather than for individuals who have smaller HNs, even if the HCNs are the same or smaller. Hence, given that QALY is accepted as the relevant outcome measure for need-based priority setting, it questions the assumption that a QALY has the same value independently of to whom it accrues.

Funding Information Open access funding provided by Linköping University.

\section{Compliance with ethical standards}

Conflict of interest The authors declare that they have no competing of interests.
Open Access This article is licensed under a Creative Commons Attribution 4.0 International License, which permits use, sharing, adaptation, distribution and reproduction in any medium or format, as long as you give appropriate credit to the original author(s) and the source, provide a link to the Creative Commons licence, and indicate if changes were made. The images or other third party material in this article are included in the article's Creative Commons licence, unless indicated otherwise in a credit line to the material. If material is not included in the article's Creative Commons licence and your intended use is not permitted by statutory regulation or exceeds the permitted use, you will need to obtain permission directly from the copyright holder. To view a copy of this licence, visit http://creativecommons.org/licenses/by/4.0/.

\section{References}

1. Hofmann B. Priority setting in health care: trends and models from Scandinavian experiences. Med Health Care Philos. 2013;16(3): 349-56.

2. Sabik LM, Lie RK. Priority setting in health care: lessons from the experiences of eight countries. Int J Equity Health. 2008;7.

3. Ministry of Health and Social Affairs. Priorities in Health Care ethics, economy, implementation. Final report from the Swedish parliamentary priorities commission (SOU 1995:5). Stockholm: Fritzes; 1995.

4. National Health Service (NHS). The NHS Constitution for England 2015 [Available from: https://assets.publishing.service.gov.uk/ government/uploads/system/uploads/attachment_data/file/480482/ NHS Constitution WEB.pdf (accessed: 2019-01-06).

5. Alakeson V. Why Oregon went wrong. BMJ. 2008;337:900-1.

6. Hadorn D. The Oregon priority-setting exercise: cost-effectiveness and the rule of rescue, revisited. Med Decis Mak. 1996;16(2):1179.

7. Hadorn DC. Setting health care priorities in Oregon. Costeffectiveness meets the rule of rescue. JAMA. 1991;265(17): 2218-25.

8. Tinghög G, Västfjäll D. Why people hate health economics - two psychological explanations. LiU Workingpapers in Economics No 6. 2018:resolve?urn=urn:nbn:se:liu:diva-148852.

9. Cookson R, Dolan P. Principles of justice in health care rationing. J Med Ethics. 2000;26(5):323-9.

10. Crisp R. Treatment according to need: justice and the British National Health Service In: Rhodes. R, editor. Medicine and Social Justice: Essays on the Distribution of Health Care. New York: Oxford University Press; 2002. p. 134-43.

11. Culyer AJ. Need: the idea won't do-but we still need it. Soc Sci Med. 1995;40(6):727-30.

12. Culyer A. Need-is a consensus possible? J Med Ethics. 1998;24(2): 77-80.

13. Hasman A, Hope T, Østerdal LP. Health care need: three interpretations. J Appl Philos. 2006;23(2):145-56.

14. Herlitz A, Horan D. Measuring needs for priority setting in healthcare planning and policy. Soc Sci Med. 2016;157:96-102.

15. Hope T, Østerdal LP, Hasman A. An inquiry into the principles of needs-based allocation of health care. Bioethics. 2010;24(9):470 80.

16. Juth N. Challenges for principles of need in health care. Health Care Anal. 2015;23(1):73-87.

17. Elmersjö CÅ, Helgesson G. Notions of just health care at three Swedish hospitals. Med Health Care Philos. 2008;11(2):145-51.

18. Gustavsson E. From needs to health care needs. Health Care Anal. 2014;22(1):22-35. 
19. Gustavsson E, Sandman L. Health-care needs and shared decisionmaking in priority-setting. Med Health Care Philos. 2014;18(1):1322.

20. Liss P-E. Health care need: meaning and measurement. Aldershot: Avebury; 1993. 141 s. p.

21. Tinghög G. The art of saying no : the economics and ethics of healthcare rationing (thesis). Linköping: Linköping University Press; 2011.

22. Marmot M, Wilkinson RG. Social determinants of health. 2. ed. Oxford ; New York: Oxford University Press; 2006. 366 p. p.

23. Hirose I. Egalitarianism. New York: Routledge; 2015.

24. Rawls J. A Theory of Justice. Cambridge: Harvard University Press; 1971. 607 s. p.

25. Temkin LS. Inequality. New York: Oxford University Press; 1993. ix, 352 s. p.

26. Temkin LS. Inequality and health. In: Eyal N, Hurst S, Norheim OF, Wikler D, editors. Inequalities in health: concepts, measures, and ethics. New York: Oxford University Press; 2013. p. 13-26.

27. Cutler D, Lleras-Muney A. Education and health: evaluating theories and evidence. In: House J, Schoeni R, Kaplan G, Pollack H, editors. Making Americans healthier: social and economic policy as health policy. New York: Russell Sage Foundation; 2008.

28. Marmot MG, Bell R. Action on health disparities in the United States commission on social determinants of health. JAMA - J Am Med Assoc. 2009;301(11):1169-71.

29. Simandan D. Rethinking the health consequences of social class and social mobility. Soc Sci Med. 2018;200:258-61.

30. Wilkinson RG, Pickett $\mathrm{K}$. The spirit level : why equality is better for everyone. Rev. ed. ed. London: Penguin; 2010.

31. Buyx AM. Personal responsibility for health as a rationing criterion: why we don't like it and why maybe we should. J Med Ethics. 2008;34(12):871-4.

32. Cappelen AW, Norheim OF. Responsibility, fairness and rationing in health care. Health Policy. 2006;76(3):312-9.

33. Sharkey K, Gillam L. Should patients with self-inflicted illness receive lower priority in access to healthcare resources? Mapping out the debate. J Med Ethics. 2010;36(11):661-5.

34. Tinghög G, Carlsson P, Lyttkens $\mathrm{CH}$. Individual responsibility for what? - a conceptual framework for exploring the suitability of private financing in a publicly funded health-care system. Health Econ Policy Law. 2010;5(2):201-23.

35. Wikler D. Personal and social responsibility for health. Ethics Int Aff. 2002;16(2):47-55.

36. Brock DW. Priority to the worse off in health care resource prioritization. Medicine and Social Justice: Essays on the Distribution of Health Care2012.

37. Crisp R. Equality, priority, and compassion. Ethics. 2003;113(4): 745-63.

38. Parfit D. Equality or Priority. Laurence: University of Kansas: The Lindley Lectures; 1995.

39. Parfit D. Another defence of the priority view. Utilitas. 2012;24(3): 399-440.

40. Casal P. Why sufficiency is not enough. Ethics. 2007;117(2):296326.
41. Frankfurt HG. Equality as a moral ideal. Ethics. 1987;98:21-43.

42. Frankfurt HG. Necessity and desire. Philos Phenomenol Res. 1984;45(1):1-13.

43. Boorse C. Health as a Theoretical Concept Philosophy of Science 1977;44:542-73.

44. Nordenfelt L. On the nature of health: an action-theoretic approach. Dordrecht: Kluwer; 1995.

45. Wiggins D. Needs, values, truth: essays in the philosophy of value. Oxford: Oxford University Press; 1998.

46. Wiggins D. An idea we cannot do without. In: Reader S, editor. The philosophy of need. Cambridge, UK: Cambridge University Press; 2005. p. 25-50.

47. Thomson G. Needs. New York: Routledge \& Kegan Paul; 1987.

48. Mill JS. Utilitarianism. Indianapolis: Bobbs-Merrill Educational Publishing; 1861.

49. Singer P. Practical ethics. Cambridge: Cambridge University Press; 1993.

50. Drummond MF, Wilson DA, Kanavos P, Ubel P, Rovira J Assessing the economic challenges posed by orphan drugs. Int $\mathrm{J}$ Technol Assess Health Care. 2007;23(1):36-42.

51. Pliskin JS, Shepard DS, Weinstein MC. Utility functions for life years and health status. Oper Res. 1980;28:206-24.

52. Bernoulli D. Exposition to a new theory on the measurement of risk. Econometrica. 1954;22(1):22-36.

53. Von Neumann J, Morgenstern O. Theory of games and economic behavior. 2. ed. Princeton, N.J.: Princeton University Press; 1947.

54. Tsuchiya A, Dolan P. The QALY model and individual preferences for health states and health profiles over time: a systematic review of the literature. Med Decis Mak. 2005;25(4):460-7.

55. Persson E, Andersson D, Back L, Davidson T, Johannisson E, Tinghög G. Discrepancy between health care rationing at the bedside and policy level. Med Decis Mak. 2018;38(7):881-7.

56. Redelmeier DA, Tversky A. Discrepancy between medical decisions for individual patients and for groups. N Engl J Med. 1990;322(16):1162-4.

57. Williams A. Economics of coronary artery bypass grafting. Br Med J (Clin Res Ed). 1985;291(6491):326-9.

58. Official Norwegian Reports (NOU 2014:12). Åpent og rettferdig prioriteringer i helsetjenesten. Oslo: Departementenes sikkerhetsog serviceorganisasjon; 2014.

59. Ottersen T, Førde R, Kakad M, Kjellevold A, Melberg HO, Moen A, et al. A new proposal for priority setting in Norway: open and fair. Health Policy. 2016;120(3):246-51.

60. Gustavsson E, Juth N. Principles of need and the aggregation thesis. Health Care Anal. 2017:1-16.

61. Ubel PA, Loewenstein G, Scanlon D, Kamlet M. Individual utilities are inconsistent with rationing choices: a partial explanation of why Oregon's cost-effectiveness list failed. Med Decis Mak. 1996;16(2): $108-16$.

Publisher's note Springer Nature remains neutral with regard to jurisdictional claims in published maps and institutional affiliations. 